\title{
Cistoadenoma de vesícula seminal
}

\section{Cystoadenoma of Seminal Vesicle}

\author{
Daniel Adri ${ }^{1}$ Alberto Layus ${ }^{2}$ Mariana Isola ${ }^{3}$ Jorge Ocantos ${ }^{1}$ \\ ${ }^{1}$ Servicio de Diagnóstico por Imágenes, Hospital Italiano de Buenos \\ Aires, Ciudad Autónoma de Buenos Aires, Argentina \\ 2 Servicio de Urología, Hospital Italiano de Buenos Aires, Ciudad \\ Autónoma de Buenos Aires, Argentina \\ ${ }^{3}$ Servicio de Anatomía Patológica, Hospital Italiano de Buenos Aires, \\ Ciudad Autónoma de Buenos Aires, Argentina
}

Rev Argent Radiol 2019;83:121-123.

Estimados Editores,

El cistoadenoma, también conocido como tumor phyllodes, ha sido definido como una neoplasia compuesta por tejido celular estromal y epitelial benigno, ${ }^{1,2}$ con sobrecrecimiento del tejido conectivo. Se caracteriza por ser una patología tumoral de predominio femenino (en mama, con una prevalencia del $0,3 \%$ al $1 \%$ ), siendo excepcional en el sexo masculino, donde afecta la próstata en primer lugar. ${ }^{2}$ Entre el año 2000 y el 2015, Reikie y col. ${ }^{3}$ informaron la existencia de 24 casos de tumores de origen epitelio estromal reportados en vesículas seminales. El objetivo de este trabajo es resaltar lo infrecuente de esa patología por medio de la presentación de un caso y la utilidad de la resonancia magnética (RM) para su estudio.

Presentamos el caso de un paciente masculino de 44 años, asintomático con único antecedente de episodio de peritonitis a los 10 años de edad. Fue derivado a nuestra institución por un hallazgo incidental en un estudio de ecografía vésico-prostática de control. Se decidió completar la caracterización realizando una RM de pelvis y vesículas seminales, en la que se reconoció una formación sólido-quística en la vesícula seminal izquierda, de bordes regulares, con componente quístico hiperintenso en secuencias ponderadas en $\mathrm{T} 1$ a expensas de contenido hemorrágico/proteico, asociado a formación vegetante interna sólida. Esas características son atribuibles a una neoplasia de origen estromal (-Figs. 1 and 2 ). El abordaje quirúrgico y el análisis anatomopatológico posterior definieron la presencia de un cistoadenoma de vesícula seminal izquierda (-Fig. 3), sin secundarismo identificable en estudios de extensión.

Clínicamente, y como en nuestro caso, el cistoadenoma puede presentarse de manera asintomática o expresarse con
Address for correspondence Daniel Adri, Servicio de Diagnóstico por Imágenes, Hospital Italiano de Buenos Aires, Ciudad Autónoma de Buenos Aires, Argentina (e-mail: danieladri33@gmail.com).

hematuria, hemospermia, síntomas obstructivos urinarios, entre otros. El rango etario de incidencia varía de 33 a 67 años. ${ }^{4}$

Teniendo en cuenta que los tumores estromales localizados en las vesículas seminales son muy infrecuentes, no hay un consenso en cuanto a la estadificación. Ella puede darse tomando la relación estroma/tejido epitelial, celularidad, necrosis o invasión de estructuras adyacentes, entre otros., Por tal razón, los estudios por imágenes resultan cruciales para la adecuada valoración de su tamaño, comportamiento y grado de compromiso de estructuras adyacentes, lo que permite contar con la mayor información para definir la conducta terapéutica y el pronóstico.

Aunque algunos autores consideran el uso de ultrasonografía como método de estudio inicial, ella debe realizarse por vía transrectal (ETR), lo que constituye un estudio invasivo, con campo de visión limitado, incapaz de establecer la extensión y de proporcionar información del contenido de las vesículas seminales ni de la lesión. Otros autores plantean que la RM, por ser un método no invasivo, con gran capacidad de discriminación tisular en diferentes secuencias, mayor resolución espacial y posibilidad de evaluar toda la pelvis en un solo paso diagnóstico, debe ser considerada el método de referencia. ${ }^{7}$

El tratamiento adecuado es la exéresis quirúrgica. La recidiva local es muy frecuente, y en los tipos histológicos más agresivos, como los sarcomas, se han reportado invasión local y metástasis pulmonares. ${ }^{8}$ Debido a que no existen parámetros de pronósticos en cuanto a la invasión locoregional, la RM representa un método no invasivo que permite ayudar a programar un tratamiento quirúrgico dirigido y especializado y continuar con un correcto seguimiento de esa patología. ${ }^{9}$ received

December 14, 2017

accepted

February 5, 2019
DOI https://doi.org/

$10.1055 / \mathrm{s}-0039-1681079$. ISSN 1852-9992.
Copyright $\odot$ 2018, Sociedad Argentina de Radiología. Publicado por Thieme Revinter Publicações Ltda., Rio de Janeiro, Brazil. Todos los derechos reservados.
License terms

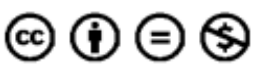



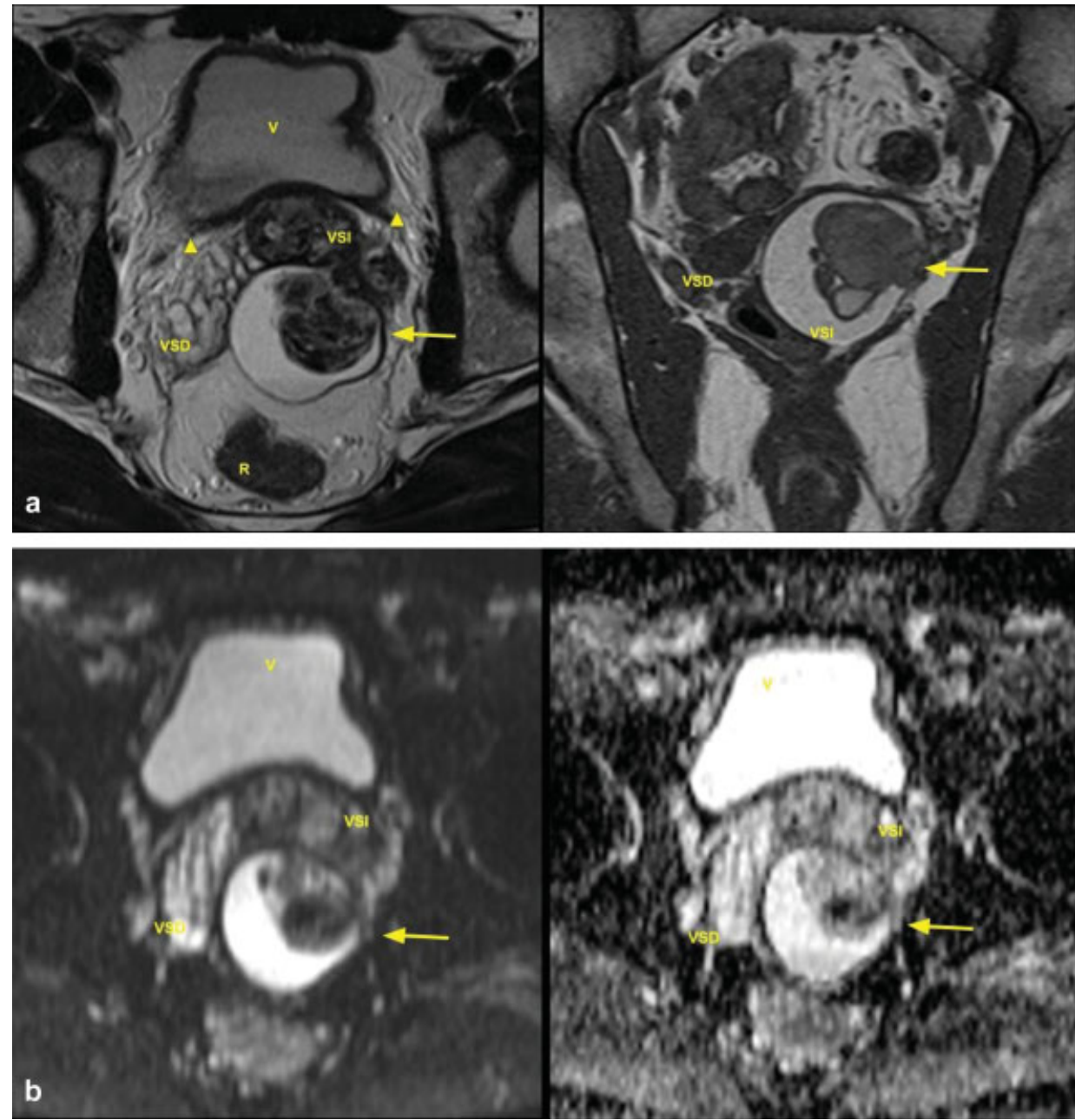

Fig. 1 Resonancia magnética (RM) de vesículas seminales plano axial ponderado en T2 y coronal ponderado en T1(a), difusión por resonancia magnética sobre valor del coeficiente de difusión aparente (DWI/ADC) (b). Formación con componente quístico de contenido hemorrágico/proteico asociado a vegetación interna sólida, sin restricción celular (flecha) ni afectación de uréteres (cabeza de flecha). Abreviación: R, recto; V, vejiga; VSD, vesícula seminal derecha; VSI, vesícula seminal izquierda.
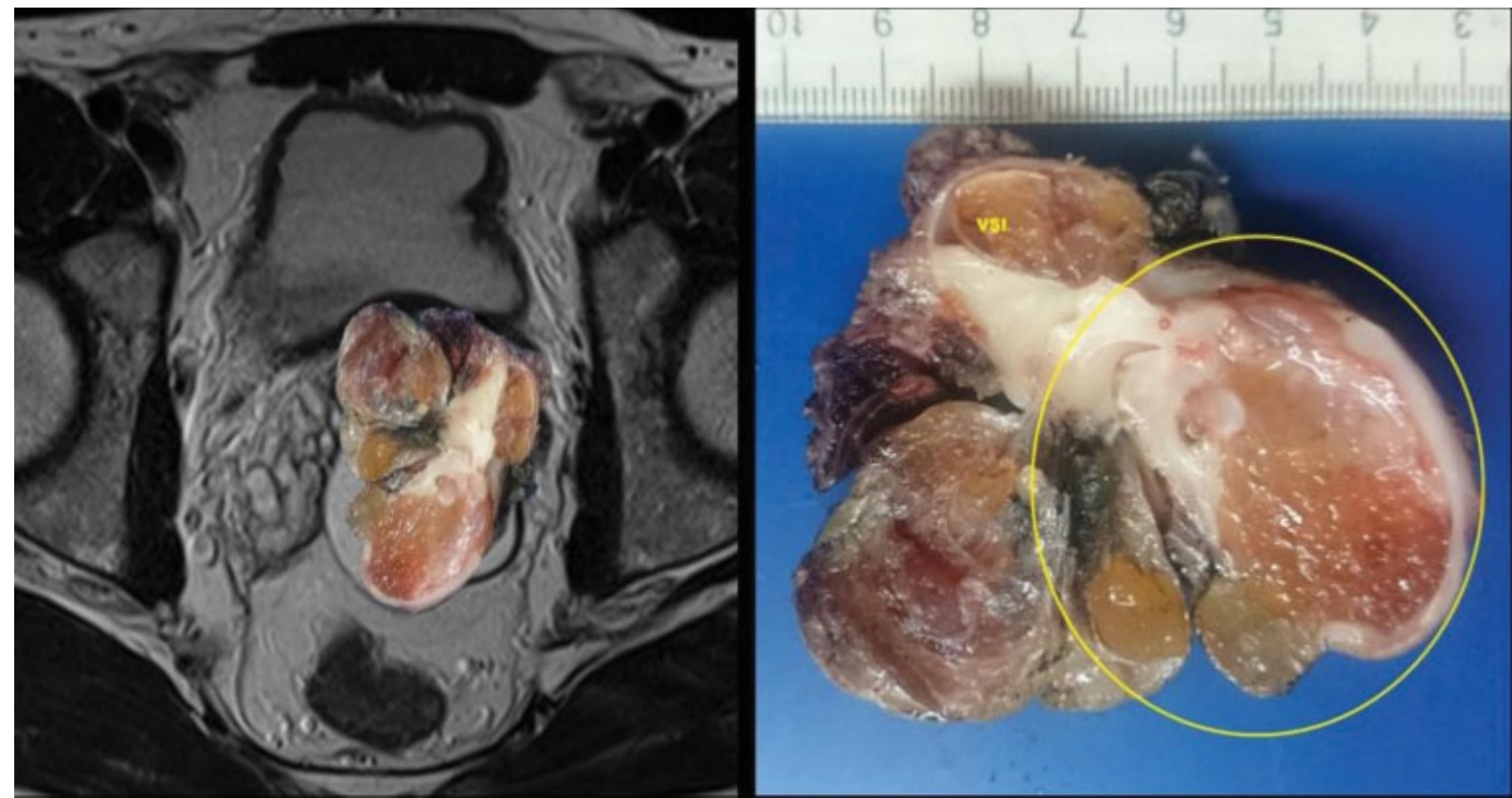

Fig. 2 Correlación anátomo-imagenológica con pieza quirúrgica macroscópica. 


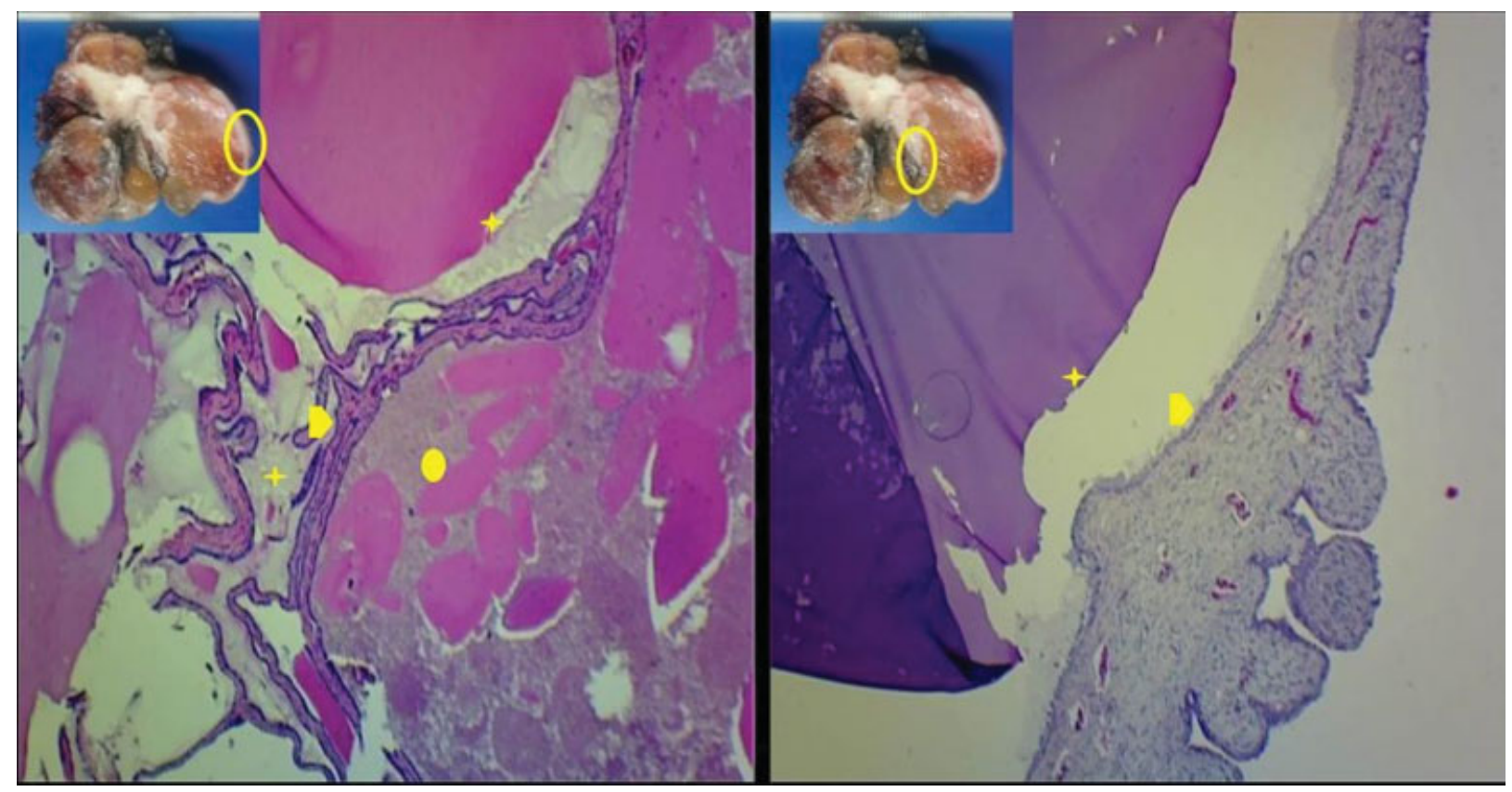

Fig. 3 Microscopía. Tinción H-E x4. Proliferación tumoral constituida por múltiples formaciones quísticas y glandulares (estrella), tapizadas por pocas capas de células epiteliales cúbicas o cilíndricas (cabeza de flecha) y cantidad variable de estroma (círculo).

Confidencialidad de los datos

Los autores declaran que han seguido los protocolos de su centro de trabajo sobre la publicación de datos de pacientes y que todos los pacientes incluidos en el estudio han recibido información suficiente y han dado su consentimiento informado por escrito para participar en dicho estudio.

\section{Conflicto de Intereses}

Los autores del trabajo declaran no tener ningún conflicto de intereses, excepto el Dr. Ocantos, que declara como posible conflicto de interés ser coautor de la referencia número 7 de la bibliografía.

\section{Bibliografía}

1 Abe H, Nishimura T, Miura T, et al. Cystosarcoma phyllodes of the seminal vesicle. Int J Urol 2002;9(10):599-601
2 Khan MS, Zaheer LU, Ahmed K, et al. Low-grade phyllodes tumor of the seminal vesicle treated with laparoscopic excision. Nat Clin Pract Urol 2007;4(07):395-400

3 Reikie BA, Yilmaz A, Medlicott S, Trpkov K. Mixed epithelialstromal tumor (MEST) of seminal vesicle: a proposal for unified nomenclature. Adv Anat Pathol 2015;22(02):113-120

4 Safar B, Kanmaniraja D, Herts BR. Phyllodes tumor of the seminal vesicle. J Urol 2014;192(02):554-555

5 Fain JS, Cosnow I, King BF, Zincke H, Bostwick DG. Cystosarcoma phyllodes of the seminal vesicle. Cancer 1993;71(06):2055-2061

$6 \mathrm{Xu} \mathrm{LW}$, Wu HY, Yu YL, Zhang ZG, Li GH. Large phyllodes tumour of the seminal vesicle: case report and literature review. J Int Med Res 2010;38(05):1861-1867

7 Ocantos J, Rey Valzacchi G, Sinclair ME, Loor Guadamud G. Resonancia magnética de vesículas seminales: un estudio no invasivo de la vía seminal. Rev Argent Urol 2010;75(02):57-62

8 Soares RO, Correia TP, Cardoso A, Cerqueira M. Tumor filoide de vesícula seminal: Caso clínico y revisión de literatura. Actas Urol Esp 2010;34(07):638-652

9 Monica B, Larosa M, Facchini F, Pozzoli G, Franceschetti I, Piscioli I. Low grade epithelial stromal tumour of the seminal vesicle. World J Surg Oncol 2008;6:101 